\title{
Oxygen-Ionic Conductors Based on Substituted Bismuth Molybdates with Column-Type Structural Fragments
}

\author{
Z. A. Mikhailovskaya ${ }^{a}$, E. S. Buyanova ${ }^{a, z}$, S. A. Petrova ${ }^{b}$, and V. M. Zhukovskii ${ }^{a}$ \\ ${ }^{a}$ Ural Federal University, Yekaterinburg, Russia \\ ${ }^{b}$ Institute of Metallurgy, Ural Branch, Russian Academy of Sciences, Yekaterinburg, Russia
}

Received June 9, 2012

\begin{abstract}
The possibility of synthesizing oxygen-ionic conductors from substituted bismuth molybdates containing $\left[\mathrm{Bi}_{12} \mathrm{O}_{14}\right]_{n}^{8 n+}$ columns, $\mathrm{MoO}_{4}$ tetrahedra, and isolated $\mathrm{Bi}$ ions in their structure was studied. The specifics of their structure and electric conductivity were investigated. The general formula of the solid solutions can be recorded as $\mathrm{Bi}_{13} \mathrm{Mo}_{5-x} \mathrm{Me}_{x} \mathrm{O}_{34-\delta}$, where $\mathrm{Me}$ is the four- or five-valent $d$ metal $(\mathrm{Ti}, \mathrm{Zr}, \mathrm{V}, \mathrm{Nb}$ ). The electric conductivity of doped bismuth molybdates considerably increased compared with that of the matrix compound. The electric conductivity reached $5.5 \times 10^{-3} \mathrm{~S} \mathrm{~cm}^{-1}$ at $700^{\circ} \mathrm{C}$ and $1.8 \times 10^{-4} \mathrm{~S} \mathrm{~cm}^{-1}$ at $350^{\circ} \mathrm{C}$ for the zirconium-doped compound with $x=0.4$. The porosity of the ceramics was less than $5 \%$; the thermal expansion coefficient was of the order of $14 \times 10^{-6} \mathrm{~K}^{-1}$. Based on the set of their characteristics, these compounds are recommended as materials for membranes of electrochemical devices.
\end{abstract}

Keywords: bismuth molybdates, oxygen-ionic conductors

DOI: $10.1134 / \mathrm{S} 1023193513070112$

\section{INTRODUCTION}

Complex oxides based on $\mathrm{Bi}_{2} \mathrm{O}_{3}$ show oxygenionic and mixed conductivity at medium temperatures $\left(300-700^{\circ} \mathrm{C}\right)$, ferroelectric and magnetic effects, and catalytic activity. Bismuth-containing compounds crystallize in structures of different types, for example, in fluorite-like structures based on $\delta-\mathrm{Bi}_{2} \mathrm{O}_{3}$ [1], layered perovskite-like structures from the BIMEVOX family [2], phases based on $\mathrm{Bi}_{26} \mathrm{Mo}_{10} \mathrm{O}_{69}$ containing $\left[\mathrm{Bi}_{12} \mathrm{O}_{14}\right]_{\infty}$ columns [3], etc. The column type of structure is especially interesting because it offers wide opportunities for selective doping and remains understudied. Studies of the $\mathrm{Bi}-\mathrm{Mo}-\mathrm{O}$ system started in the 1940-50s primarily in view of the high catalytic activity of bismuth molybdates in olefin oxidation reactions. The region with high bismuth content has become the object of investigation only since the late 1990s. In 1996-1997, a new structural type was revealed by single-crystal $\mathrm{X}$-ray diffraction for monoclinic compounds $\mathrm{Bi}_{13} \mathrm{Mo}_{5} \mathrm{O}_{34.5}$ and $\mathrm{Bi}_{13} \mathrm{Mo}_{4} \mathrm{VO}_{34}$ (space group $P 2 / c$ ) in the $\mathrm{Bi}_{2} \mathrm{O}_{3}-\mathrm{MoO}_{3}-\mathrm{V}_{2} \mathrm{O}_{5}$ system. The structures of these unique compounds, having no analogs among other complex oxides based on bismuth oxide, contain $\left[\mathrm{Bi}_{12} \mathrm{O}_{14}\right]_{n}^{8 n+}$ column-type fragments parallel to the $Y$ axis, layers of $(\mathrm{Mo} / \mathrm{V}) \mathrm{O}_{4}$ tetrahedra parallel to the (100) and (001) planes, and isolated $\mathrm{Bi}$ atoms also lying in layers among tetrahedra

\footnotetext{
${ }^{z}$ Corresponding author: Elena.Buyanova@usu.ru (E.S. Buyanova).
}

$[4,5]$. This type of structure anisotropy is rarely met in other bismuth-containing complex oxides and shows itself as the anisotropy of properties. Later, it was found that the structure provided ion transport along the crystal-chemical direction of column fragments ( $y$ axis) [6]. The compounds have oxygen-ionic conductivity; they can compete with BIMEVOX and YSZ in electric conductivity [7] and hence are an alternative electrolytic material for gas-discharge membranes, separators, sensors, and fuel cells.

As shown in [4], the composition of $\mathrm{Bi}_{13} \mathrm{Mo}_{5} \mathrm{O}_{34.5}$ can be varied in the bismuth content from $\mathrm{Bi}_{12.875} \mathrm{Mo}_{5} \mathrm{O}_{\delta}$ to $\mathrm{Bi}_{13.875} \mathrm{Mo}_{5} \mathrm{O}_{\delta}$, forming solid solutions. The range in which the solid solutions exist was evaluated in [5] as a wider range with excess bismuth: from $1.43 \mathrm{Bi}_{2} \mathrm{O}_{3}: 1 \mathrm{MoO}_{3}$ to $1.75 \mathrm{Bi}_{2} \mathrm{O}_{3}: 1 \mathrm{MoO}_{3}$, which corresponds to the formulas $\mathrm{Bi}_{14.3} \mathrm{Mo}_{5} \mathrm{O}_{\delta}$ and $\mathrm{Bi}_{17.5} \mathrm{Mo}_{5} \mathrm{O}_{\delta}$. Bismuth deficiency can be created by partial replacement by molybdenum (the replacement of the $\mathrm{BiO}_{4} \mathrm{E}$ trigonal bipyramid, where $\mathrm{E}$ is the isolated electron pair of bismuth and/or the $\mathrm{BiO}_{3} \mathrm{E}$ tetrahedron, by the $\mathrm{MoO}_{4}$ tetrahedron in the given range of concentrations). It was also stated [5] that the unit cell of bismuth molybdate $\left(\mathrm{Bi}_{13} \mathrm{Mo}_{5} \mathrm{O}_{34.5}, Z=2\right)$ formally contained only 68 crystal-chemical positions for 69 oxygen atoms irrespective of the presence or absence of the metal dopant. The initial formula $\mathrm{Bi}_{13} \mathrm{Mo}_{5} \mathrm{O}_{34.5}$ was thus transformed into $\mathrm{Bi}_{13} \mathrm{Mo}_{5} \mathrm{O}_{34 \pm \delta}$.

Further studies sought metal dopants for modifying the physicochemical properties of the compounds. 
The compound $\mathrm{PbBi}_{12} \mathrm{Mo}_{5} \mathrm{O}_{34}$, was synthesized from ordinary oxides by the standard ceramic technology and studied in [8]. It was shown that lead atoms were not incorporated in $\left[\mathrm{Bi}_{12} \mathrm{O}_{14}\right]_{n}$ column structures, but selectively occupied the isolated bismuth positions in the layers of molybdenum-oxygen tetrahedra. The only examples of the replacement of bismuth by metal atoms in the column structure are compounds corresponding to the formula $\mathrm{Bi}\left(\mathrm{Bi}_{12}{ }_{-}{ }_{x} \mathrm{Te}_{x} \mathrm{O}_{14}\right) \mathrm{Mo}_{4-x} \mathrm{~V}_{1+x} \mathrm{O}_{20}$, $0 \leq x \leq 2.5[9,10]$ obtained by replacing $\mathrm{Bi}^{3+}$ by $\mathrm{Te}^{4+}$ and of $\mathrm{Mo}^{6+}$ by $\mathrm{V}^{5+}$ in the matrix of $\mathrm{Bi}_{13} \mathrm{Mo}_{4} \mathrm{VO}_{34}$. It was shown that $\mathrm{Bi}\left(\mathrm{Bi}_{12-x} \mathrm{Te}_{x} \mathrm{O}_{14}\right) \mathrm{Mo}_{4-x} \mathrm{~V}_{1+x} \mathrm{O}_{20}$ had a total electric conductivity of $7.96 \times 10^{-3} \mathrm{~S} \mathrm{~cm}^{-1}$ for $x=1$ at $1023 \mathrm{~K}$ [10]. A study of the possibility of replacing molybdenum by differently charged cations in $\mathrm{Bi}_{13} \mathrm{Mo}_{5} \mathrm{O}_{34 \pm \delta}$ was described in [11]. The replacing cations were chosen to be $\mathrm{Li}^{+}, \mathrm{Mg}^{2+}, \mathrm{Al}^{3+}, \mathrm{Si}^{4+}, \mathrm{Ge}^{4+}$, and $\mathrm{V}^{5+}$. All of the synthesized compounds corresponded to the structure of the starting matrix; the conductivity maximum was observed for the composition $\mathrm{Bi}_{13} \mathrm{Mo}_{4.667} \mathrm{Al}_{0.333} \mathrm{O}_{34}\left(1.4 \times 10^{-2} \mathrm{~S} \mathrm{~cm}^{-1}\right.$ at $\left.980 \mathrm{~K}\right)$. The effects of the replacement of isolated bismuth atoms by rare-earth elements in molybdates, which changed the electric conductivity of the compounds, were studied in [12]. In the series under study with rareearth substituents ( $\mathrm{La}, \mathrm{Nd}, \mathrm{Gd}, \mathrm{Ho}, \mathrm{Yb}$, and the vacancy $\square), \mathrm{Ln}_{2 / 3} \square_{1 / 3}\left[\mathrm{Bi}_{12} \mathrm{O}_{14}\right]\left(\mathrm{MoO}_{4}\right)_{5}$ showed a parabolic dependence of electric conductivity on composition with a maximum for $\mathrm{Ln}=\mathrm{Gd}\left(6.6 \times 10^{-3} \mathrm{~S} \mathrm{~cm}^{-1}\right.$ at $973 \mathrm{~K})$.

In this study, we synthesized complex oxides with a column-type structure substituted in the molybdenum sublattice and having the general formula $\mathrm{Bi}_{13} \mathrm{Mo}_{5-x} \mathrm{Me}_{x} \mathrm{O}_{34-\delta}$, where $\mathrm{Me}=$ four- and five-valent $d$ metals $(\mathrm{T}, \mathrm{V}, \mathrm{Zr}$, and $\mathrm{Nb}$ ) and investigated their conductivity.

\section{EXPERIMENTAL}

Solid solutions of the general formula $\mathrm{Bi}_{13} \mathrm{Mo}_{5-x} \mathrm{Me}_{x} \mathrm{O}_{34-\delta}$ were synthesized by the standard ceramic procedure at $773-1123 \mathrm{~K}$ at a step of $50 \mathrm{~K}$. The starting components were bismuth oxide $\mathrm{Bi}_{2} \mathrm{O}_{3}$ (ultra high grade), molybdenum oxide $\mathrm{MoO}_{3}$ (ultra high grade), titanium oxide $\mathrm{TiO}_{2}$ (ultra high grade), vanadium oxide $\mathrm{V}_{2} \mathrm{O}_{5}$ (ultra high grade), niobium oxide $\mathrm{Nb}_{2} \mathrm{O}_{5}$ (ultra high grade), and zirconium oxide $\mathrm{ZrO}_{2}$ (ultra high grade).

The starting substances were preliminarily calcinated in a furnace at $873-1073 \mathrm{~K}$ to remove traces of moisture and mixed in a stoichiometric ratio. After each stage of synthesis, the samples were cooled together with the furnace and carefully ground in an agate mortar with an ethanol addition as a homogenizing agent.

The phase composition of the intermediates and end products was determined by XRD (Bruker ADVANCE D8 diffractometer, position-sensitive VANTEC sensor, $\mathrm{Cu} K_{\alpha}$ radiation, $2 \theta=10-70 \mathrm{deg}$, rate $2 \mathrm{deg} / \mathrm{min}$ ). The unit cell parameters were calcu- lated and the crystal structure refined with FPeaK, Celref, and FullProf program packages [13]. The phases were identified using the ICDD, COD, and AMSCD card files.

The characteristics of the powders were determined by laser diffraction (SALD-7101 Shimadzu laser analyzer of dispersity), densitometric analysis, and atomic emission analysis (iCAP 6500 Thermo Scientific spectrometer with inductively coupled plasma). The differential thermal analysis was performed in the temperature range 293-973 K using an STA 409 PC Luxx Netzsch thermoanalyzer. Alumina was used as a standard. For electric conductivity studies, the powders of the phases were preformed into briquets with a diameter of $10 \mathrm{~mm}$ and sintered at $1123 \mathrm{~K}$ (final temperature of synthesis) for $24 \mathrm{~h}$. The density of the sintered preformed samples was calculated from the pycnometric specific gravity and bulk density of the ceramics. The bulk density was determined by hydrostatic weighing. The surface of the sintered samples was studied by electron microscopy (JEOL JSM 6390LA scanning electron microscope). The dilatometric studies of the ceramics were performed by impedance spectroscopy on a DIL 402C Netzsch dilatometer (Elins Z-3000 impedance meter) at $1123-523 \mathrm{~K}$.

\section{RESULTS AND DISCUSSION}

Series of solid solutions of the general composition $\mathrm{Bi}_{13} \mathrm{Mo}_{5-x} \mathrm{Me}_{x} \mathrm{O}_{34-\delta}(\mathrm{Me}=\mathrm{Ti}, \mathrm{V}, \mathrm{Zr}$, and $\mathrm{Nb}$, i.e., metals with a tetrahedral coordination to oxygen) with $x=0.2-1.0$ were synthesized by the standard ceramic method. The homogeneity ranges were determined by XRD for all series under study. The widest homogeneity range (up to $x=1.0$ ) was observed for $\mathrm{Bi}_{13} \mathrm{Mo}_{5-x} \mathrm{~V}_{x} \mathrm{O}_{34-\delta}$ solid solutions, which agrees with the data of $[4,5]$. For titanium- and niobium-doped compounds, the formation of solid solutions was limited to $x=0.2$. Further increase in the content of the metal dopant led to the isolation of molybdates $\mathrm{Bi}_{38} \mathrm{Mo}_{7} \mathrm{O}_{78}$ and $\gamma-\mathrm{Bi}_{2} \mathrm{MoO}_{6}$, complex bismuth oxides, and $3-25 \%$ metal dopant. The introduction of zirconium led to the formation of solid solutions based on $\mathrm{Bi}_{13} \mathrm{Mo}_{5} \mathrm{O}_{34 \pm \delta}$ with $x$ of up to 0.4 . The formation of solid solutions was accompanied by a monotonic change in the unit cell parameters (Table 1).

The formation of solid solutions is provided not only by the closeness of the radii of ions in tetrahedral environments $\left(r_{\mathrm{Mo}^{6+}}=0.41 \AA, r_{\mathrm{V}^{5+}}=0.35 \AA, r_{\mathrm{Ti}^{4+}}=0.42 \AA\right.$, $r_{\mathrm{Nb}^{5+}}=0.48 \AA$, and $r_{\mathrm{Zr}^{4+}}=0.59 \AA$ ) in all cases [14]. The ionic radius of zirconium differs from that of molybdenum in the tetrahedral environment by $\sim 43 \%$, disobeying the rule of the ratio of sizes of substituent components in a solid solution. The efficiency of substitution in this case is determined by the fact that disordered molybdenum-oxygen polyhedra do not form rigid bonds with the structural columnar fragments. Due to this, the region of solid solutions can be sub- 
Table 1. Crystal data for monophase compositions $\mathrm{Bi}_{13} \mathrm{Mo}_{5-x} \mathrm{Me}_{x} \mathrm{O}_{34-\delta}$ and their XRD and pycnometric densities

\begin{tabular}{l|c|c|c|c|c|c}
\hline \multirow{2}{*}{ Composition } & \multicolumn{5}{|c|}{ Unit cell parameters } & \multirow{2}{*}{$\begin{array}{c}\text { Pycnometric } \\
\text { densities, } \mathrm{g} / \mathrm{cm}^{3}\end{array}$} \\
\cline { 2 - 5 } & $a, \AA$ & $b, \AA$ & $c, \AA$ & $\beta,^{\circ}$ & $V, \AA^{3}$ & 7.64 \\
$\mathrm{Bi}_{13} \mathrm{Mo}_{4.8} \mathrm{Zr}_{0.2} \mathrm{O}_{34-\delta}$ & 11.753 & 5.799 & 24.807 & 102.91 & 1647.99 & 7.64 \\
$\mathrm{Bi}_{13} \mathrm{Mo}_{4.6} \mathrm{Zr}_{0.4} \mathrm{O}_{34-\delta}$ & 11.748 & 5.800 & 24.810 & 102.95 & 1647.51 & 7.44 \\
$\mathrm{Bi}_{13} \mathrm{Mo}_{4.8} \mathrm{~V}_{0.2} \mathrm{O}_{34-\delta}$ & 11.727 & 5.799 & 24.706 & 102.20 & 1642.18 & 7.27 \\
$\mathrm{Bi}_{13} \mathrm{Mo}_{4.6} \mathrm{~V}_{0.4} \mathrm{O}_{34-\delta}$ & 11.715 & 5.798 & 24.658 & 102.41 & 1635.73 & 7.43 \\
$\mathrm{Bi}_{13} \mathrm{Mo}_{4.4} \mathrm{~V}_{0.6} \mathrm{O}_{34-\delta}$ & 11.703 & 5.798 & 24.607 & 102.64 & 1629.21 & 7.50 \\
$\mathrm{Bi}_{13} \mathrm{Mo}_{4.2} \mathrm{~V}_{0.8} \mathrm{O}_{34-\delta}$ & 11.694 & 5.802 & 24.507 & 102.44 & 1623.72 & 7.52 \\
$\mathrm{Bi}_{13} \mathrm{Mo}_{4} \mathrm{VO}_{34-\delta}$ & 11.688 & 5.805 & 24.266 & 100.72 & 1617.68 & 7.78 \\
$\mathrm{Bi}_{13} \mathrm{Mo}_{4.8} \mathrm{Nb}_{0.2} \mathrm{O}_{34-\delta}$ & 11.757 & 5.803 & 24.749 & 102.88 & 1646.03 & 7.65 \\
$\mathrm{Bi}_{13} \mathrm{Mo}_{4.8} \mathrm{Ti}_{0.2} \mathrm{O}_{34-\delta}$ & 11.787 & 5.805 & 24.740 & 102.94 & 1649.81 & 7.52 \\
$\mathrm{Bi}_{13} \mathrm{Mo}_{5} \mathrm{O}_{34 \pm \delta}$ & 11.801 & 5.805 & 24.740 & 102.82 & 1650.35 & \\
\hline
\end{tabular}

stantially enlarged within the given structure. This is illustrated by the structure of $\mathrm{Bi}_{13} \mathrm{Mo}_{5-x} \mathrm{Me}_{x} \mathrm{O}_{34-\delta}$ in Fig. 1.

The element composition of solid solutions determined by atomic emission analysis corresponds to the nominal ratio set during the synthesis. Densitometric analysis showed that the pycnometric density agreed with the XRD density within the error (Table 1). The particle size of the powders varied from 1 to $10 \mu \mathrm{m}$.

To evaluate the thermal stability of the samples, we performed high-temperature studies (differential scanning calorimetry combined with thermogravimetric analysis). The sample mass did not change and the thermal effects were absent at $420-1120 \mathrm{~K}$ for all compositions under study. This points to the absence of phase transitions and decomposition of complex oxides in this temperature range in air.

The surface of the sintered briquets was studied by scanning electron microscopy. Figure 2 shows the micrographs of the surface of the briquets formed from the monophase and nonmonophase zirconium-doped bismuth molybdate powders. The grain size increased relative to the powder particle size, but was much smaller in the nonmonophase sample because the impurity phase hindered recrystallization and block enlargement. For monophase samples, dense ceramic briquets with less than $5 \%$ porosity formed, which was proven by hydrostatic measurements. Dilatometric studies allowed us to calculate the average thermal expansion coefficient for all series of solid solutions $\left(14 \times 10^{-6} \mathrm{~K}^{-1}\right)$, which is the characteristic index for electrolytic ceramics.

The electric conductivity of the solid solutions was studied by impedance spectroscopy at $523-1123 \mathrm{~K}$. Measurements were performed by the double-contact method using platinum electrodes on preliminarily prepared sintered briquets. The typical hodographs are given for one sample at different temperatures in Figs. 3 and 4. The given form of dependence is characteristic of all compositions under study. An equivalent circuit of the
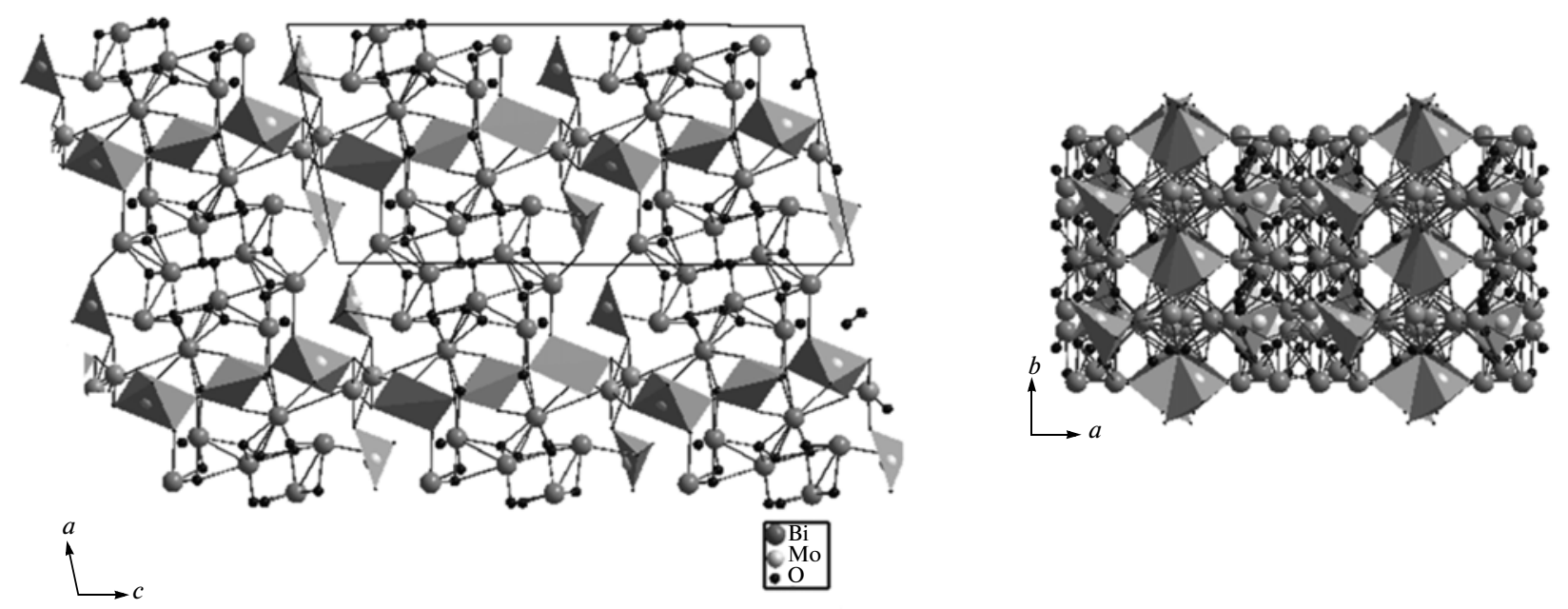

Fig. 1. Structure of $\mathrm{Bi}_{13} \mathrm{Mo}_{5-x} \mathrm{Me}_{x} \mathrm{O}_{34-\delta}$ solid solutions projected to the (xoz) (left) and (xoy) (right) planes. The disordered oxygen-molybdenum elements of the structure are shown as polyhedra. 


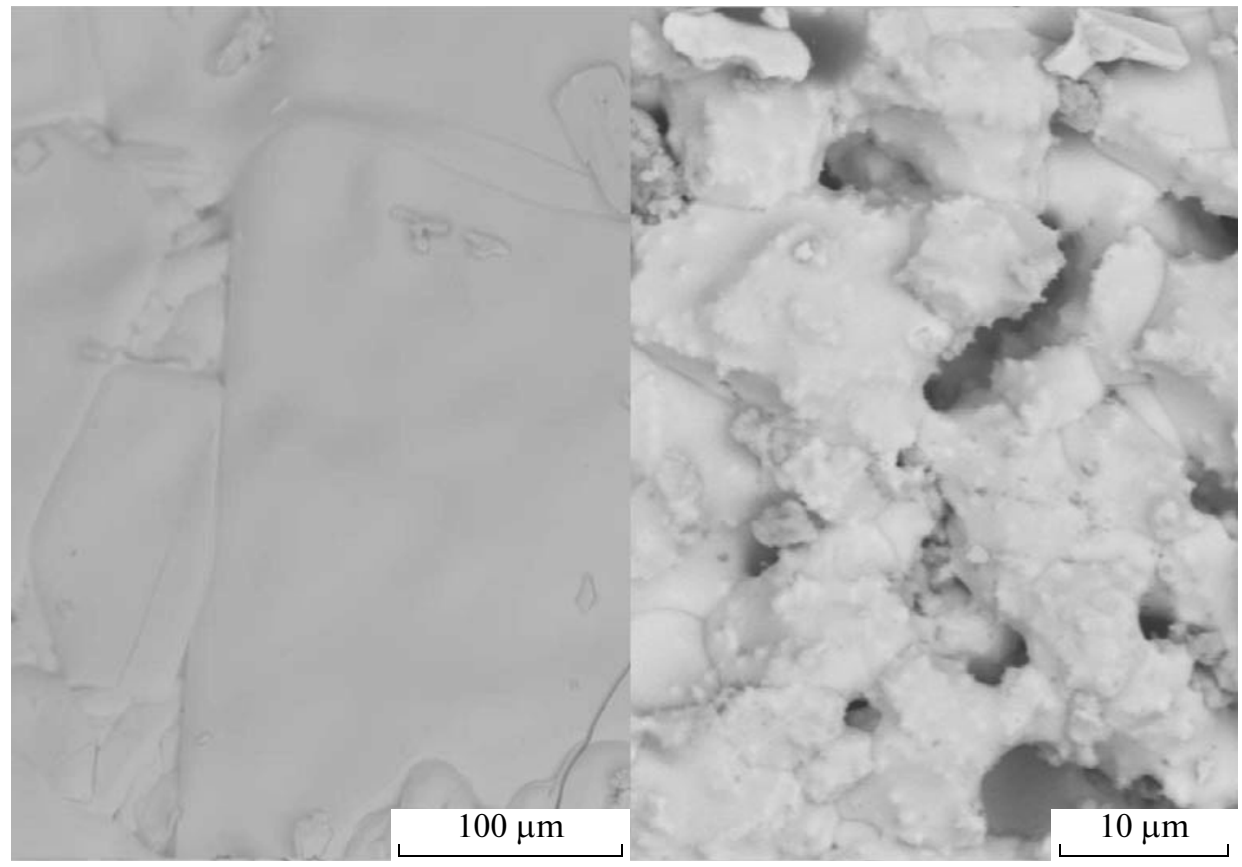

Fig. 2. Micrographs of the surface of $\mathrm{Bi}_{13} \mathrm{Mo}_{5-x} \mathrm{Me}_{x} \mathrm{O}_{34-\delta}$ briquets for the monophase (left) and nonmonophase (right) samples.

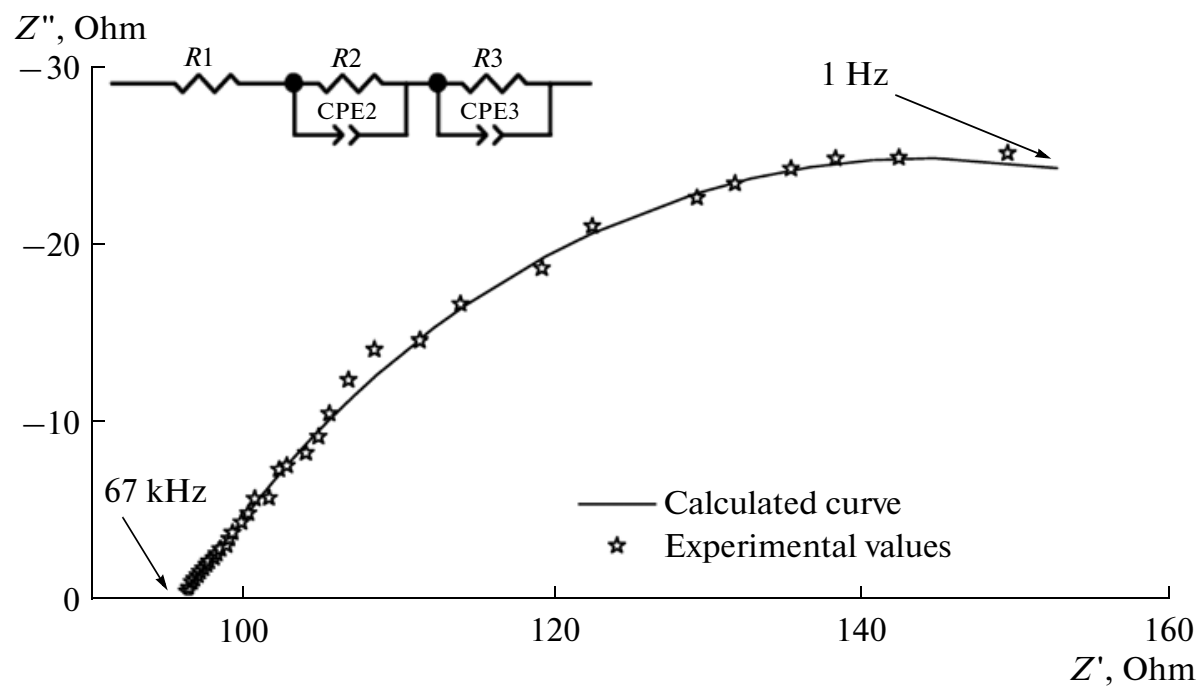

Fig. 3. Typical hodographs at high temperatures and an equivalent circuit for the processes. Recording at $850^{\circ} \mathrm{C}$.

cell corresponding to processes in a definite temperature range was chosen using the Zview software program (Version 2.6b, Scribner Associates).

The shape of the dependence of the imaginary part of complex resistance on the real part changed with temperature. At relatively low temperatures, the impedance diagram has an asymmetric semicircle. Then the impedance curve smoothly transforms, after a minimum, into a line with a slope of $45^{\circ}$. For the low-temperature region, the cell circuit is thus a sequential connection of resistances $R 1$ and $R 2$ with CPE1 and CPE2 elements connected in parallel and characterizing the electrolyte material and the closed Warburg element $W 1$ (Fig. 4). The CPE type elements in the equivalent circuit are the elements of the constant phase. The equation for admittance for them is recorded as $Y(\omega)=B(j \omega)^{n}$. It contains two parameters whose values affect the imitation of various electrical elements by the CPE element.

The $R 1$ resistance connected in parallel to the CPE1 element corresponds to the bulk conductivity of the sample, while $R 2$ connected with CPE2 corresponds to the grain boundary resistance of grains (and their sum corresponds to the total resistance). Thus 


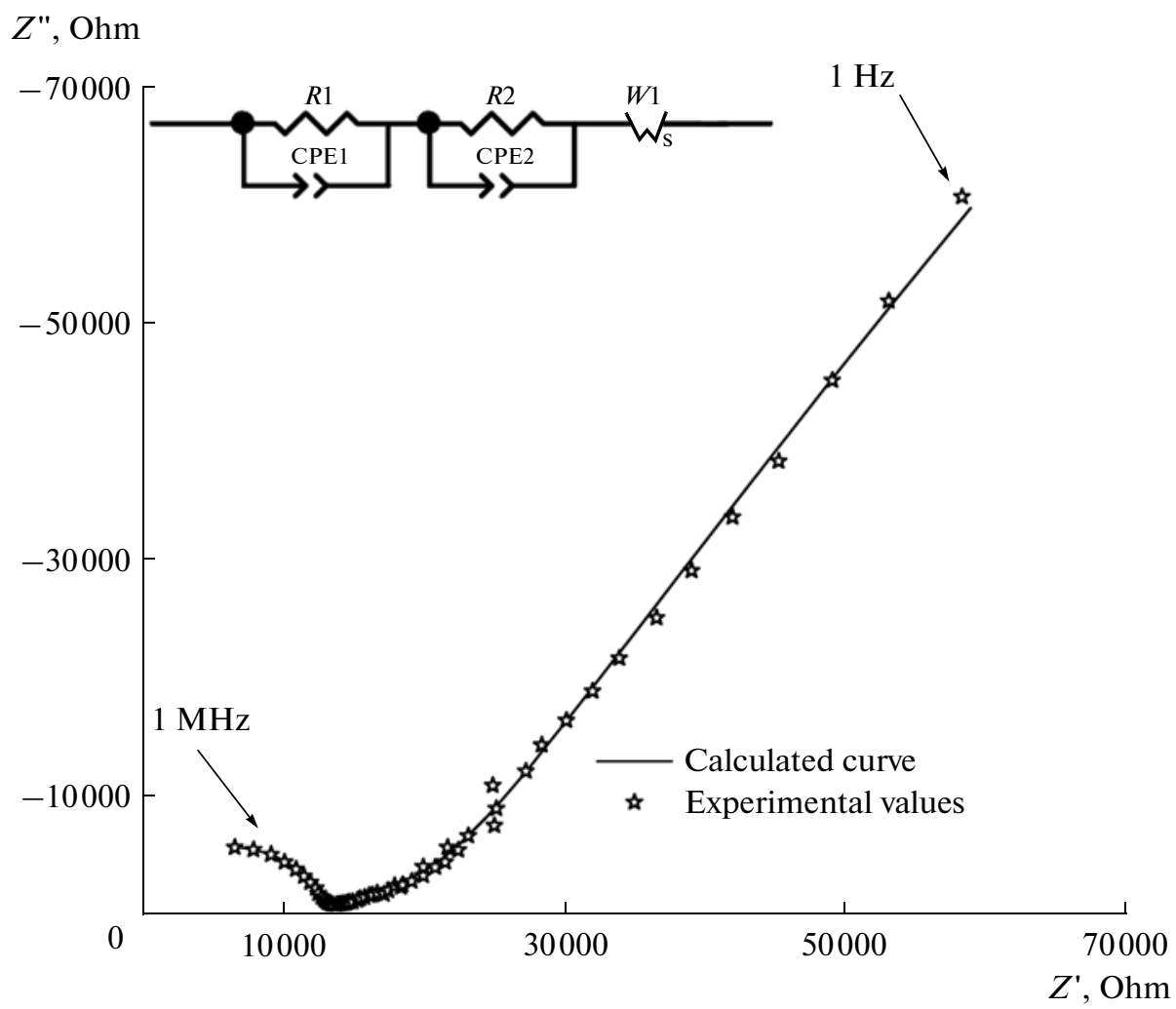

Fig. 4. Typical hodographs at moderate temperatures and an equivalent circuit for the processes. Recording at $350^{\circ} \mathrm{C}$.

the conductivity of a polycrystalline sample at low temperatures was calculated from $R 1+R 2$. The Warburg element $W_{\mathrm{s}}$ describes the diffusion, which is the

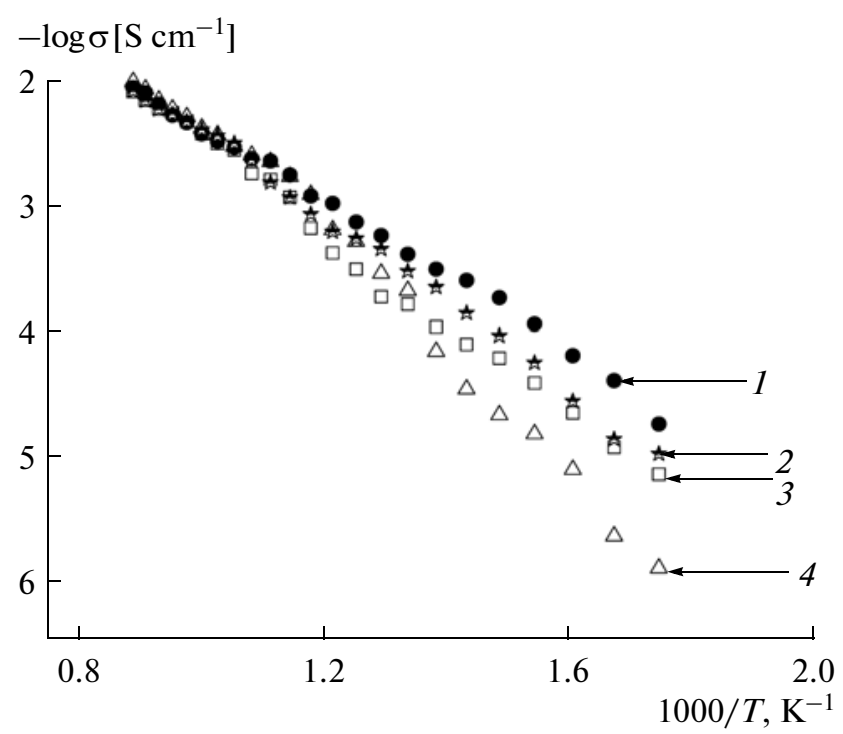

Fig. 5. Temperature dependences of electric conductivity for substituted bismuth molybdates $\mathrm{Bi}_{13} \mathrm{Mo}_{4.8} \mathrm{Me}_{0.2} \mathrm{O}_{34-\delta}$ : (1) $\mathrm{Bi}_{13} \mathrm{Mo}_{4.8} \mathrm{~V}_{0.2} \mathrm{O}_{34-\delta}, \quad$ (2) $\mathrm{Bi}_{13} \mathrm{Mo}_{4.8} \mathrm{Zr}_{0.2} \mathrm{O}_{34-\delta}$, (3) $\mathrm{Bi}_{13} \mathrm{Mo}_{4.8} \mathrm{Nb}_{0.2} \mathrm{O}_{34-\delta}$, and (4) $\mathrm{Bi}_{13} \mathrm{Mo}_{4.8} \mathrm{Ti}_{0.2} \mathrm{O}_{34-\delta}$. prevailing factor in the given temperature range. The CPE2 and CPE1 capacities are of the order of $10^{-7}$ and $10^{-11} \mathrm{~F}$, which allows us to attribute them to the bulk and grain-boundary conductivity, respectively [15].

At elevated temperatures, the oxygen diffusion and adsorption on electrodes are considerably facilitated, and the circuit does not contain the Warburg element any longer (Fig. 3). The impedance diagram is a semicircle with a smaller radius that changes into a semicircle with a larger radius. The small semicircle (the $R 2$ junction and CPE2) may be attributed to grainboundary resistance, while the semicircle corresponding to the bulk resistance is leveled and characterized only by the resistance $R 1$. As in the case of low temperatures, the total resistance is characterized by the sum of $R 1$ and $R 2$. The parallel connection of $R 3$ and CPE 3 then describes the electrode processes in the system being measured, which are not fixed at low temperatures against the background of diffusion processes. The CPE2 "capacity" is of the order of $10^{-11} \mathrm{~F}$ and CPE3 is $10^{-6} \mathrm{~F}$, which is characteristic of oxide systems.

The total electric conductivities calculated from impedance measurements are represented as the plots of the temperature dependences of conductivity of the chosen compositions and as tables of electrophysical characteristics (Fig. 5 and Table 2). 
Table 2. Electrophysical characteristics of solid solutions of the composition $\mathrm{Bi}_{13} \mathrm{Mo}_{5-x} \mathrm{Me}_{x} \mathrm{O}_{34-\delta}$

\begin{tabular}{l|c|c|c}
\hline \multicolumn{1}{c|}{ Composition } & $\sigma_{700}, \mathrm{~S} \mathrm{~cm}^{-1}$ & $\sigma_{350}, \mathrm{~S} \mathrm{~cm}^{-1}$ & $E_{\mathrm{a}}, \mathrm{eV}$ \\
\hline $\mathrm{Bi}_{13} \mathrm{Mo}_{5} \mathrm{O}_{34} \delta$ & $1.2 \times 10^{-3}$ & $2.5 \times 10^{-6}$ & 0.73 \\
$\mathrm{Bi}_{13} \mathrm{Mo}_{4.8} \mathrm{Ti}_{0.2} \mathrm{O}_{34-\delta}$ & $3.4 \times 10^{-3}$ & $7.0 \times 10^{-6}$ & 0.60 (above 500 \\
$\mathrm{Bi}_{13} \mathrm{Mo}_{4.8} \mathrm{Nb}_{0.2} \mathrm{O}_{34-\delta}, 1.1$ (below 500 & 0.65 \\
$\mathrm{Bi}_{13} \mathrm{Mo}_{4.8} \mathrm{Zr}_{0.2} \mathrm{O}_{34-\delta}$ & $4.6 \times 10^{-3}$ & $5.6 \times 10^{-5}$ & 0.60 \\
$\mathrm{Bi}_{13} \mathrm{Mo}_{4.6} \mathrm{Zr}_{0.4} \mathrm{O}_{34-\delta}$ & $4.4 \times 10^{-3}$ & $2.5 \times 10^{-5}$ & 0.53 \\
$\mathrm{Bi}_{13} \mathrm{Mo}_{4.8} \mathrm{~V}_{0.2} \mathrm{O}_{34-\delta}$ & $5.5 \times 10^{-3}$ & $1.8 \times 10^{-4}$ & 0.60 \\
$\mathrm{Bi}_{13} \mathrm{Mo}_{4.6} \mathrm{~V}_{0.4} \mathrm{O}_{34-\delta}$ & $3.0 \times 10^{-3}$ & $5.8 \times 10^{-5}$ & 0.65 \\
$\mathrm{Bi}_{13} \mathrm{Mo}_{4.4} \mathrm{~V}_{0.6} \mathrm{O}_{34-\delta}$ & $2.0 \times 10^{-3}$ & $1.8 \times 10^{-5}$ & 0.79 \\
$\mathrm{Bi}_{13} \mathrm{Mo}_{4.2} \mathrm{~V}_{0.8} \mathrm{O}_{34-\delta}$ & $1.2 \times 10^{-3}$ & $1.7 \times 10^{-5}$ & 0.78 \\
$\mathrm{Bi}_{13} \mathrm{Mo}_{4} \mathrm{VO}_{34-\delta}$ & $1.1 \times 10^{-3}$ & $6.9 \times 10^{-6}$ & 0.86 \\
\hline
\end{tabular}

The general view of the temperature dependences of conductivity (Fig. 5) for the complex oxides under study is typical for ionic conductors. The dependences $\log \sigma-10^{3} / T$ for the majority of compounds have no distinct inflections or bends of linear segments, which confirms the absence of phase transitions and agrees with high-temperature dilatometric and thermogravimetric studies. For titanium-doped compounds, however, the activation energy changed from 0.6 to $1.1 \mathrm{eV}$ when the temperature decreased below $500^{\circ} \mathrm{C}$ (Fig. 5, Table 2). This was observed [11] for bismuth molybdate doped with silicon and germanium and explained by a change in the molybdenum coordination and hence by a rearrangement of molybdenum-oxygen polyhedra within the framework of the starting symmetry on the basis of high-temperature XRD data. Similar changes might take place in the titanium-doped compound in the structure of $\mathrm{Bi}_{13} \mathrm{Mo}_{5-x} \mathrm{Me}_{x} \mathrm{O}_{34-\delta}$, which requires further studies.

In the doped compound, the specific electric conductivity generally increases relative to that in nondoped $\mathrm{Bi}_{13} \mathrm{Mo}_{5} \mathrm{O}_{34 \pm \delta}$. For series of solid solutions, the concentration dependences of conductivity are nonmonotonic. The maximum values of conductivity were obtained for the composition $\mathrm{Bi}_{13} \mathrm{Mo}_{4.6} \mathrm{Zr}_{0.4} \mathrm{O}_{34-\delta}$ (Table 2). The decrease in conductivity at higher dopant concentrations may be caused by a change in the concentration of defects in the oxygen sublattice. The number of oxygen vacancies decreased on passing from octahedral to tetrahe- dral environment of molybdenum. Moreover, the probability of vacancy-dopant interactions, forming less mobile defect complexes, increases at higher dopant concentrations.

On the other hand, according to [7], an increase in the oxygen vacancy concentration after the introduction of a heterovalent dopant does not significantly affect the oxygen diffusion in column structures. The type of the environment of molybdenum and the character of the motion of oxygen ions along the [010] crystallographic direction, i.e., of $\left[\mathrm{Bi}_{12} \mathrm{O}_{14}\right]$ columns, where the geometrical hindrances to ion motion are minimum, play the main role. This may be the reason for the insignificant difference in the conductivity of solid solutions at high temperatures.

Based on high conductivities of substituted bismuth molybdates, we can assert that the compounds under study are promising as electrolytes at medium temperatures. Due to low porosity, the absence of phase transitions, and medium thermal expansion coefficients, these electrolytes can be recommended as membrane materials for electrochemical devices.

\section{ACKNOWLEDGMENTS}

This study was financially supported by the Russian Foundation for Basic Research, grant no. 12-0300464, no. 12-03-31119, within the program of scientific research competition for post-graduate and undergraduate students of the Ural Federal University. 


\section{REFERENCES}

1. Boivin, J.C., Int. J. Inorg. Mat., 2001, vol. 3, p. 1261.

2. Abraham, F., Boivin, J.C., Mairesse, G., and Nowogrocki, G., Solid State Ionics, 1990, vols. 40-41, p. 934.

3. Fonseca, F.C., Steil, M.C., Vannier, R.N., Mairesse, G., and Muccillo, R., Solid State Ionics, 2001, vol. 140, p. 161.

4. Enjalbert, R., Hasselmann, G., and Galy, J., J. Solid State Chem., 1997, vol. 131, p. 236.

5. Vannier, R.N., Mairesse, G., Abraham, F., and Nowogrocki, G., J. Solid State Chem., 1996, vol. 122, p. 394.

6. Bastide, B., Villain, S., Salles, P., and Galy, J., Solid State Sci., 2002, vol. 4, p. 599.

7. Vannier, R.N., Danze, S., Nowogrocki, G., Huve, M., and Mairesse, G., Solid State Ionics, 2000, vols. 136-137, p. 51 .
8. Enjalbert, R., Hasselmann, G., and Galy, J., Acta Crystallgr.: Sect. C, vol. 53, p. 269.

9. Castro, A., Enjalbert, R., Baules, P., and Galy, J., J. Solid State Chem., 1998, vol. 139, p. 185.

10. Begue, P., Rojo, J.M., Enjalbert, R., Galy, J., and Castro, A., Solid State Ionics, 1998, vol. 112, p. 275.

11. Bastide, B., Enjalbert, R., Salles, P., and Galy, J., Solid State Ionics, 2003, vol. 158, p. 351.

12. Galy, J., Salles, P., Rozier, P., and Castro, A., Solid State Ionics, 2006, vol. 177, p. 2897.

13. Rodriguez-Carvajal, J., Physica A, vol. 192, p. 55.

14. Shannon, R.D., Acta Crystallogr., 1976, vol. 32, p. 751.

15. Irvine, J.T.S., Sinclair, D.C., and West, A.R., Adv. Mater., 1990, vol. 2, p. 132.

Translated by L. Smolina 